\title{
The adoption of a programme for creative development among young school-age children with regard to considerations of gender
}

\author{
Larisa Litvinova ${ }^{1, *}$, Zarine Khachanyan ${ }^{2}$, Madina Botasheva ${ }^{3}$, Oksana Lobozova ${ }^{1}$ \\ ${ }^{1}$ Stavropol State Medical University, 310 Mira str., Stavropol, 355017, Russia \\ ${ }^{2}$ Stavropol Center for Extracurricular Activities, 4 Osetinskaya str., Stavropol, 355029, Russia \\ ${ }^{3}$ Dagestan State Medical University, 1 Lenin sq., Makhachkala, 367000, Russia
}

\begin{abstract}
The age- and role-related growth of young school-age children is made possible by psychophysiological processes, among them gender role behaviour. Our research makes it possible to define the correlative link between creativity and lateralisation, which affects the motivation of boys and girls differently. Art therapy with girls showed a very strong prediliction towards independence and risk-taking against a background of middling self-sufficiency. Work with boys demonstrated a negative tendency for dependence on the opinions of others against a background of heightened hopes of success. Participants reacted strongly to the requirement to display the results of their creative art therapy work, and were generally apprehensive of the reaction of others to, and the social validation of, what they had done. This research shows the need to either segregate boys and girls into different groups or set separate tasks for each sex, thus reducing competition. The former experience positive changes in the strength and lability of the nervous system, as well as improved sensitivity.
\end{abstract}

\section{Introduction}

Modern psychology refers to taking an individual approach to solving some kind of task or problem as "creativity". This concept is related to the system of intellectual and personal characteristics which enable subjects to engage in their affairs in an individual - and, generally speaking, original - way. Research in this area upholds the view that creativity can be developed via specialised training $[1,2]$.

Childhood offers fertile ground upon which to stimulate creativity in this manner [3, 4]. The early years of school are worthy of particular consideration, as it is at this stage of life that a child gains new duties, forms a sense of responsibility, and begins to interact with his or her peers and teachers in a new way, fulfulling new roles in the classroom [5-8].

In order to evaluate creativity at this age it is necessary to assess the structure and detail of the young child's role behaviour [9, 10]. As is well known, our roles differentiate the internal and external aspects of our lives. Learning gradually takes primacy after we enter

\footnotetext{
* Corresponding author: larisa-litva@yandex.ru
} 
school, coming with time to affect the child's entire system of relationships and changing it; the social situation of development and the social status of the child change, and new responsibilities appear, bringing with them evaluation by the outside world [11-13].

As a result, behaviour changes, manifesting itself in children of this age as affectation, mannerisms, artificial tension, independence and self-sufficiency, obstinacy and determination $[9,11]$. These behavioural reactions are temporary and stem from the transition from one age to another, but they are nonetheless unavoidably accompanied by misbehaviour, argument and heightened sensitivity to stress [12-14].

Along with spontaneity, children gain the ability to analyse and systematise incoming data, which is otherwise expressed in creative work and make-believe $[15,16]$. The results of creative imagination possess a raft of characteristics, the most important of which are: a) the complete determination (organisation) of all elements of a difficult situation for an actor in them; b) a need for mental (conscious) reinforcement of the product of creativity in a concrete, tangible form; c) intuitive grouping; d) an incomplete grasp of both the underlying inspiration for the product of creativity and e) its potential consequences (ie. the existence of a well of possible, frequently unexpected applications for it); and f) a need for acts of comprehension, the subject's understanding of the definition of both creative works extant in general culture and those which the subject has himself created.

Bearing in mind age- and role-related changes, we must turn to the results of empirical research [17, 18]. Their analysis of the psychological conditions surrounding the development of creativity determined that the most important factor was children's individual psychophysiological traits, comprising verbal and non-verbal intellect, the development of the ability to reason, and the psycholinguistic characteristics of improvised speech.

They discovered that young school-age children's non-verbal creativity is affected by the functional asymmetry of the brain's hemispheres and the tempo of activity. This became visible in data on flexibility, originality and development. The tempo of right-hand activity among 10-year-olds correlated positively with the degree of completion of the stimulatory figure in the Torrance test, which was connected with the tendency of children of that age towards visual reasoning. The researchers concluded that non-verbal creativity among young schoolchildren is connected to the functional asymmetry of the brain's hemispheres and the tempo of activity.

Earlier investigation of hemispheric asymetry and lateral profiles has shown a close connection between the lateralisation of functions and levels of motivation [19], implying that motivation may also be correlated with creativity. This raises a need to thoroughly research how creativity and motivation are connected in young school-age children. Work has been carried out into the structure of giftedness and how it is related to academic motivation; however, behaviour as related to gender differences has not been analysed thus far.

Analysing the work mentioned above has enabled us to hypothesise that there is a correlational connection between creativity and lateralisation, and that this will manifest itself differently in boys and girls of grade school age.

\section{Material and method}

Sixty-five children from schools in the city of Stavropol participated in the research. The control phase (CP) and data-gathering phase (DP) of the experiment took place in mid-term in order to allow for adaptation to the new emotional environment and academic workload. The DP programme was comprised of lessons using art therapy to train new forms of creativity. They took place at times convenient to the children, taking into account their normal schoolwork. 
The following methods were chosen to investigate the children's lateralisation and motivation: the Ilyin tapping test and the Heckhausen motivation test.

The tapping test measures the changes in the speed of movement of the hand over a defined period of time. This assists in determining the basic characteristics of the central nervous system and researching the level of acceptance, evaluation and analysis of the information received as well as its subsequent application. In view of the age of the participants, a standard 30-second window was ideal to record data and research the flow of cognitive processes. During the experiment it became evident that the most important test information was fixed during a 20-25 second period, during which the main aims of the tapping test - diagnosing changes in the central nervous system and recording the speed of hand movements - were carried out. As a rule, moderate and intensive loads were the main cause of fatigue related to the autonomic nervous system. Work at maximum intensity leads to the development of extreme inhibition directly inside the nerve centres, a feature on which the test is based: it measures the tolerance of the nervous system when testing is conducted at maximum speed.

Heinz Heckhausen's motivational test was presented as a questionnaire. The reliability of the results of both methods was checked using the Mann-Whitney U-Test.

\section{Results}

Analysis of the results of the tapping test during the control phase revealed a variety of traits of the nervous system in young schoolchildren. Children of 11 years of age displayed an initial reduction in maximum right-hand speed, which gave way to a short-lived return to the speed recorded at the outset. This pattern of maximum speed is described as the "dip" type. As a consequence of their temporary rise in pace, these test subjects can be classified as having a moderate-to-weak right-hand nervous system, with a tolerance (as measured by the number of strikes by the right hand) of below average (4 points out of a possible 10).

When it came to the left hand, both sexes maintained roughly the same maximum speed throughout the test period. The resulting type, curved, characterises the left-hand nervous system of 11-year-olds as one of medium strength, with a low (2 out of 10) tolerance as measured by the number of strikes by the left hand.

Both sexes reliably displayed lateralisation of hand movements at the beginning and in the middle of the test (Table 1). As the end of the test approached the number of strikes by each hand became more equal.

Table 1. Trends in Maximum Speed of Movements in Boys and Girls.

\begin{tabular}{|c|c|c|c|c|c|c|c|}
\hline & & \multicolumn{5}{|c|}{ Number of strikes } & \\
\hline $\begin{array}{c}\text { Squar } \\
\text { e }\end{array}$ & Time & \multicolumn{2}{|c|}{ Boys } & \multicolumn{2}{c|}{ Girls } & \\
\hline $\begin{array}{c}\text { No. } \\
\text { Period } \\
\text { (s) }\end{array}$ & $\begin{array}{c}\text { Right } \\
\text { hand }\end{array}$ & $\begin{array}{c}\text { Left } \\
\text { hand }\end{array}$ & p $^{\mathbf{1}}$ & $\begin{array}{c}\text { Right } \\
\text { hand }\end{array}$ & $\begin{array}{c}\text { Left } \\
\text { hand }\end{array}$ & p $^{\mathbf{2}}$ \\
\hline 1 & $0-5$ & 29.91 & 18.73 & $\leq 0.001^{*}$ & 33.57 & 21.14 & $\leq 0.001^{*}$ \\
\hline 2 & $6-10$ & 25.27 & 18.27 & $\leq 0.005^{*}$ & 26.43 & 16.86 & $\leq 0.001^{*}$ \\
\hline 3 & $11-15$ & 24.09 & 15.82 & $\leq 0.001^{*}$ & 23.71 & 16.57 & $\leq 0.001^{*}$ \\
\hline 4 & $16-20$ & 21.91 & 17.00 & $\leq 0.001^{*}$ & 24.14 & 17.00 & $\leq 0.05^{*}$ \\
\hline 5 & $21-25$ & 31.09 & 16.45 & $\leq 0.001^{*}$ & 32.57 & 14.86 & $\leq 0.001^{*}$ \\
\hline 6 & $26-30$ & 19.73 & 18.36 & $>0.05$ & 17.57 & 20.43 & $>0.05$ \\
\hline
\end{tabular}

Art therapy made a considerable difference to the strength and lability of the 11-yearolds' central nervous systems. The maximum speed of the movements of their left and right hands moved markedly towards those of the "level" type, in which the maximum speed 
remains at approximately the same level throughout the duration of the test, testifying to a welcome improvement in the strength of the children's neural processes after therapy.

Analysing the left- and right-hand data for girls and boys reveals symmetry in the maximum number of movements after the DP (Table2). As the symmetry primarily affects right-sided schoolchildren, we can propose that the test subjects formed a compensatory mechanism, which in turn signals a bright future for their adaptation to physical and psychological stress at school and at home. The rise in the number of strikes by the left hand shows that the right hemisphere of the brain has been activated, which bodes well for the children's adaptability and emotional state.

Table 2. Trends in Maximum Speed of Movements in Boys and Girls After DP.

\begin{tabular}{|c|l|l|l|l|l|l|c|}
\hline & & \multicolumn{5}{|c|}{ Number of strikes } & \\
\hline Square & \multicolumn{1}{|c|}{ Time } & \multicolumn{2}{|c|}{ Boys } & \multicolumn{2}{c|}{ Girls } & \\
\hline No. & Period (s) & $\begin{array}{c}\text { Right } \\
\text { hand }\end{array}$ & $\begin{array}{c}\text { Left } \\
\text { hand }\end{array}$ & $\mathbf{p}^{\mathbf{1}}$ & $\begin{array}{c}\text { Right } \\
\text { hand }\end{array}$ & $\begin{array}{c}\text { Left } \\
\text { hand }\end{array}$ & $\mathbf{p}^{\mathbf{2}}$ \\
\hline 1 & $0-5$ & 39.00 & 36.29 & $>0.05$ & 34.00 & 31.88 & $>0.05$ \\
\hline 2 & $6-10$ & 33.21 & 27.14 & $\leq 0.05^{*}$ & 32.38 & 27.63 & $>0.05$ \\
\hline 3 & $11-15$ & 26.64 & 23.14 & $>0.05$ & 28.88 & 24.13 & $>0.05$ \\
\hline 4 & $16-20$ & 25.79 & 25.50 & $>0.05$ & 27.63 & 28.75 & $>0.05$ \\
\hline 5 & $21-25$ & 29.64 & 28.29 & $>0.05$ & 28.63 & 27.63 & $>0.05$ \\
\hline 6 & $26-30$ & 27.71 & 25.79 & $>0.05$ & 26.50 & 26.13 & $>0.05$ \\
\hline
\end{tabular}

Both sexes experienced the same change in central nervous system tolerance levels. In comparison with the control results, the total number of strikes with the right hand rose from below average (4) to average level (6); the increase for the left hand was from low (2) to average (5). Bear in mind, however, that physical and mental stamina are not direct indications of the strength of the nervous system, although they are connected to it. In this case we are dealing with the stamina of nerve cells, not of the child. Improving tolerance levels in young schoolchildren reflects an increased reserve of strength in the central nervous system of children who have taken part in art therapy.

The following trends were observed in gender differences: in comparison with the control phase, boys' right-hand lability rose from below average (3) to above-average (7), while the left-hand value went from low (2) to average (6). Girls' right-hand tolerance remained steady at average (5), and the left hand jumped from low (2) to below-average (4).

At the heart of the lability of the central nervous system lies the assimilation of the rhythm of impulses entering tissue. The higher the frequency with which any particular system is able to react, the greater its lability. This trait benefits academic success and intellectual activity. Mental flexibility is one component of the lability of the nervous system, and is responsible for switching between processes of excitation and inhibition. Since the stream of information requiring assimilation, processing and analysis is constant and enormous, there is a need to process stimuli and classify them as important or unimportant in the shortest possible time. In academia this manifests itself as a very high level of mental development and an ability to analyse incoming information logically.

The results obtained for the schoolchildren from the Heckhausen Motivational Tendencies Test were also very valid. The test determines two main themes: Expectation of Success (ES) and Fear of Failure (FF). Both reflect motivation to achieve to a greater or lesser degree. The FF value is subdivided into Sense of Personal Inadequacy (FF1) and Fear of Social Consequences of Failure (FF2).

During the control phase young school-age children demonstrated a moderate ES and low FF1 and FF2 values. Diagnostic data for the children testified to a moderate tendency overall. At this age young schoolchildren have generally not yet developed a high level of 
assertiveness and, as is characteristic of middling ES scores, are incapable of independently choosing either their aims or how to achieve them.

The low FF scores have a negative correlation with success at school. Academic success in junior school, unlike senior school, reflects the necessary level of assertiveness in schoolchildren and points to a reduced sense of personal inadequacy in tackling challenges.

Heckhausen himself believed that the fundamental aim of any activity was related to addressing a set task and that the task itself would be seen as unachievable in the absence of a clear target, in which case the subject's own ability to solve the problem becomes the measure of his evaluation of his actions. Compulsory participation in the activity then becomes a necessary condition of this evaluation.

The DP art programme took the above factors into account, and the art therapy exercises undertaken were within the capabilities of even the weakest student, providing a true picture of the development of the components of creativity in all the test subjects.

Retesting the children on completion of the DP showed a change in all aspects of motivation levels, and FF2 values for boys rose significantly more than for girls $(p \leq 0.05)$, raising the need to analyse the data by sex.

Among boys, the greatest changes occurred in ES and FF2. Prior to DP the overall level of motivation had hovered around the average and below-average level, but after DP both rose to high. All aspects of girls' motivation levels also changed but, unlike boys, the significant change was on the ES scale $(\mathrm{p} \leq 0.05)$, whereas the increase in FF2 levels was within the expected norm. Levels of assertiveness remained moderate, reflecting girl's openness to social evaluation of their work and creative abilities. 


\section{Discussion}

Analysis of the results of the experiment showed that before DP the young schoolchildren had a resilient average tendency for self-sufficiency and risk-taking $(b=3.36)$. During the experiment some girls' predisposition to success increased, while others' declined $(b=10.78)$. Of note, this was unconnected with their sense of personal inadequacy, inasmuch as this value fell.

Motivation to achieve is known to be associated with competition with fellow group members, although at the same time some have a greater chance of success. We believe that it is this which caused the rise in ES levels among boys, although the required validity level was not reached $(\mathrm{p}>0.05)$. While some boys displayed a marked increase in assertiveness and risk-taking, others overestimated their abilities. Analysis of the traits which influenced success in art therapy exercises confirmed high levels of intersquare divergence $(b=10.94)$. This psychological transformation brought about a marked tendency among boys towards self-sufficiency when taking decisions and choosing approaches to the task set.

It is worth noting that fear of social evaluation is related to the choice of sphere of activity and, depending on the sphere chosen, can directly affect changes in motivational tendencies. As far as we can see, boys of this age react very strongly to the need to demonstrate the results of their work during art therapy. Those who succeeding at the tasks demonstrated a moderate FF2 and expected negative reactions from adults and their classmates to a lesser extent than those who grappled with the tasks with less success, who were more worried about the reaction from those around them and the social evaluation of their work $(\mathrm{p} \leq 0.05)$.

\section{Conclusion}

The results of the data gathered in our investigation of motivation among young school-age children returned significant gender differences in all aspects and defined art therapy techniques as a way to actualise self-sufficiency among young schoolchildren. The tangible results of the training sessions, ie. the artworks, raised the level of assertiveness in boys more so than in girls, and the production of a creative work (as the result of activity) was, for some, a weak spot. Criticism by an adult or fellow-student caused suffering and damaged their self-esteem.

Comparative analysis of the results has led us to the conclusion that taking part in art therapy lessons in order to develop creativity has a different effect on young boys from that which it has on girls. The former experience positive changes in the strength and lability of the nervous system, as well as improved sensitivity. The ability of girls to carry out creative tasks successfully has a negative effect on levels of competitiveness among boys of this age.

It is therefore possible to conclude that there is a need to hold separate creativity development lessons for boys and girls. Should the educational process not permit separate classes, it is desirable to set different tasks in order to reduce competition. Omitting a formal marking system is also an important factor in the practical work of the art therapist with young school-age children.

\section{References}

1. M.A. Runco, R.S. Albert, Creativity Research. The Cambridge Handbook of Creativity (Cambridge University Press, 2010) ISBN 978-0-521-73025-9 
2. J. Biddulph, J. Cariss, Reimagining Professional Development in Schools, 164-185 (2020) DOI: 10.4324/9780429293337-12

3. J. Bean, Consumption Markets and Culture 18(2) (2015) DOI: $10.1080 / 10253866.2014 .889875$

4. D.M. Wonderly, E.S. Fleming, Exceptional children 31(8), 405-9 (1965) DOI: $10.1177 / 001440296503100803$

5. M. Carcamo-Solís, de L., M. Arroyo-Lopez, del P., L. Alvarez-Castanon, E. del C., García-Lopez, Teaching and Teacher Education 64, 291-304 (2017) DOI: 10.1016/j.tate.2017.02.013

6. O.V. Burenkova, A. Podturkin, New Directions for Child and Adolescent Development 169, 97-115 (2020) DOI: 10.1002/cad.20330

7. L. Goubert, T. Vervoort, Tijdschrift voor Geneeskunde 70(21), 1240-1248 (2014) DOI: 10.2143/TVG.70.21.2001721

8. A. Whitney, The Educational Forum 80(3), 353-364 (2016) DOI: $10.1080 / 00131725.2016 .1173153$

9. E. Clarke, Behaviour Management and the Role of the Teaching Assistant, 17-24 (2020) DOI: $10.4324 / 9780429057434-2$

10. R. Willans, M-F. Faulkner, The Multicultural Dimension of the National Curriculum, 212-222 (2020) DOI: 10.4324/9780203761403-16

11. D. Pendergast, Teaching Primary Years, 43-63 (2020) DOI: 10.4324/9781003117797-3

12. A. Saiti, Educational Management Administration \& Leadership 43(4) (2014) DOI: $10.1177 / 1741143214523007$

13. S. Lozynska, I. Sadova, M. Pantiuk, Proceedings of the International Scientific Conference 2, 339 (2019) DOI: 10.17770/sie2019vol2.3889

14. S.A. Sokolenko, I.I. Chepurko, Conference: All-Russian Scientific and Practical Conference (2019) DOI: 10.31483/r-53603

15. J. Roper, G. Cheney, Corporate Governance International Journal of Business in Society 5(3), 95-104 (2005) DOI: 10.1108/14720700510604733

16. S. Heilbrunn, International Education Studies 3(2), 174-184 (2010) DOI:10.5539/ies.v3n2p174

17. M.A. Davis, Organizational Behavior and Human Decision Processes 100/1, 25-38 (2009) doi:10.1016/j.obhdp.2008.04.001

18. C. Nowakowska, C.M. Strong, C.M. Santosa, P.W. Wang, T.A. Ketter, J Affect Disord. March 85/1-2, 207-215 (2005) doi:10.1016/j.jad.2003.11.012

19. De Dreu M. Baas, K.W. Carsten, B.A. Nijstad, Psychological Bulletin. November 134/6, 779-806 (2008) doi:10.1037/a0012815. 